\title{
Bundling forest ecosystem services for FSC certification: an analysis of stakeholder adaptability
}

\author{
W. JAUNGa, , G.Q. BULL a , L. PUTZEL ${ }^{b}$, R. KOZAK ${ }^{a}$ and C. ELLIOTT"a,c \\ ${ }^{a}$ University of British Columbia, 2424 Main Mall, Vancouver, BC, V6T 1Z4, Canada \\ ${ }^{b}$ Center for International Forestry Research, Jalan CIFOR, Bogor, 16000, Indonesia \\ ${ }^{c}$ Climate and Land Use Alliance, 235 Montgomery Street, 13th Floor, San Francisco, 94104, CA, USA
}

Email: w.jaung@alumni.ubc.ca, gary.bull@ubc.ca,1.putzel@cgiar.org,rob.kozak@ubc.ca, chris.elliott@clua.net

\begin{abstract}
SUMMARY
An expansion of Forest Stewardship Council (FSC) certification to forest ecosystem services (FES) is a potential tool to improve FES management. Certification of FES in bundles is an expected strategy because it could decrease trade-offs among FES, increase forest owners' incomes, and reduce certification costs per FES. However, there is insufficient evidence of which bundles FES would be most feasible to certify. This study assesses the adaptability of the FSC system to FES bundles through analyses of FES projects and surveys of FSC certification bodies, enabling partners, and certificate holders. Exploratory factor analysis and multiple correspondence analysis identified two bundles: 1) soil and watershed conservation and 2) cultural ecotourism with non-timber forest products or agricultural goods. These findings indicate potentially manageable FES bundles, given the current FSC system and FES projects, as well as some implementation challenges.
\end{abstract}

Keywords: certification of forest ecosystem services, ecosystem services bundles, Forest Stewardship Council (FSC), forest certification

\section{La certification FSC de bouquets de services écosystémique: Analyse de l'adaptabilité des parties prenantes à une intégration des services forestiers}

\author{
W. JAUNG, G.Q. BULL, L. PUTZEL, R. KOZAK et C. ELLIOTT
}

Une expansion du système de certification du Forest Stewardship Council (FSC) à la certification des services écosystémiques forestiers (SEF), est un outil qui a un potentiel d'améliorer la gestion des SEF. La certification de SEF en bouquets de services écosystémiques est une stratégie prévisible car elle pourrait diminuer les compromis dans les choix relatifs entre SEF, augmenter les revenus des propriétaires forestiers, et réduire les coûts de certification par rapport à ceux des SEF calculés individuellement. Il existe cependant une insuffisance de résultats concrets concernant des groupages particuliers de SEF, qui seraient les plus appropriés pour être certifier conjointement. Cette étude évalue l'adaptabilité du système FSC à une éventuelle certification de différents bouquets de SEF à travers une analyse de projets SEF d'une part, et des enquêtes menées auprès d'organismes de certification, de partenaires du FSC, et de détenteurs de certificats d'autre part. L'analyse factorielle exploratoire et l'analyse des correspondances multiples indiquent deux bouquets de SEF qui ont une faisabilité élevée. Le premier bouquet est constitué de la conservation des sols et des services des bassins versants, et le deuxième bouquet comporte l'écotourisme culturel avec des produits non ligneux de forêt ou des produits agricoles. Les résultats de cette étude indiquent certains groupages de SEF avec une bonne faisabilité et qui sont potentiellement gérables et discutent aussi les contraintes de mise en œuvre liées au fonctionnement actuel du système FSC et des projets SEF.

La agrupación de servicios de los ecosistemas forestales para la certificación del Consejo de Administración Forestal: Un análisis de la capacidad de adaptación de las partes interesadas

\author{
W. JAUNG, G.Q. BULL, L. PUTZEL, R. KOZAK y C. ELLIOTT
}

La expansión del Consejo de Administración Forestal (CAF) a los servicios ambientales forestales (SAF) es una herramienta con el potencial para mejorar la gestión de SAF. La certificación SAF por paquetes es una estrategia aconsejable, ya que podría disminuir las compensaciones entre SAF, aumentar los ingresos de los propietarios del bosque, y reducir los costos de certificación por SAF. Sin embargo, no existe evidencia suficiente sobre cuáles paquetes de SAF se pueden certificar. Este estudio evalúa la capacidad de adaptación del sistema CAF para paquetes de SAF a través de un análisis de proyectos de SAF y encuestas a los organismos de certificación CAF, socios de apoyo, y los tenedores de certificados. Un análisis factorial exploratorio y un análisis de correspondencias múltiples identificaron dos paquetes: 1) conservación de suelos y cuencas hidrográficas, y 2) ecoturismo cultural con productos forestales no maderables o productos agrícolas. Estos hallazgos revelan que existen paquetes de SAF potencialmente manejables, dado el actual sistema CAF y proyectos SAF, así como algunos problemas en su aplicación. 


\section{INTRODUCTION}

Since the early 1990s, Forest Stewardship Council (FSC) forest certification has been implemented globally to promote sustainable forest management and mitigate illegal logging and biodiversity loss (Auld \& Bull 2003, Cashore et al. 2006, Elliott \& Schlaepfer 2001). Based on consumer confidence that certified products derive from more sustainable management, FSC forest certification has been found to contribute to improved forest governance (Cerutti et al. 2011, Pettenella \& Brotto 2012) and communication among stakeholders (Tsanga et al. 2014). However, the system also faces limitations, such as high costs and limited uptake in low-income countries (Durst et al. 2006).

Since its inception, the FSC system has received attention for its potential application to certification of forest ecosystem services (FES) (Bass \& Simula 1999, Griscom et al. 2014, Jaung et al. 2006, Merger et al. 2011, Pettenella \& Brotto 2012, Rametsteiner \& Simula 2003, Vogt et al. 2000). We use the term FES to denote any benefit of forest ecosystems to society, such as regulation of water discharge rates, provision of non-timber forest products (NTFPs), and mitigation of climate change through carbon sequestration (MA 2005). Beyond these indispensable benefits, FES represent many market opportunities, once of which is the potential for the FSC to expand ${ }^{1}$ the scope of certification.

The Principles and Criteria upon which FSC certification is predicated are linked in many ways to management of FES, as they require management of biodiversity, NTFPs, watershed, and soil (FSC 2012). Several studies link forest certification to better management of FES, including forest biodiversity (e.g. Medjibe et al. 2013, Nasi et al. 2012) and watersheds (e.g. Dias et al. 2015). In comparing various FES, FSC stakeholders' adaptability has been identified as relatively high for functions related to biodiversity conservation, carbon storage, and NTFPs, medium for those associated with watershed protection services, and low for those dealing with ecotourism and agricultural products (Jaung et al. 2016). However, the FSC system has limitations in the way it addresses management of FES, particularly in targeting markets where service credits are traded (e.g., forest carbon market and REDD+). The FSC system manages FES only as a part of sustainable timber production; it does not quantify delivery of FES, such as a specific amount of carbon sequestrated or a degree of improved water quality (Gan and Cashore 2013, van Dam et al. 2010). Thus, the application of FSC certification to FES is expected to require a fundamental expansion of the system from development of FES standards through management and oversight, in effect a new certification scheme which might be called FES certification.

An expansion of FSC is likely to include certification of several groupings of FES produced through the same management practices, or FES bundles (e.g., Deal et al. 2012). The feasibility of certifying various different bundles would affect a number of enabling conditions of FES certification. First, many FES are produced in complementary and tradeoff relationships (Bennett et al. 2009, Raudsepp-Hearne et al. 2010, Rodríguez et al. 2006); certification of FES bundles could maximize the former but minimize the latter. Second, through the promise of increased income at limited costs, certification of FES bundles could enhance the market by increasing forest owners' demand for FES certification (Deal et al. 2012, Kemkes et al. 2010, Robertson et al. 2014). Third, certification of FES bundles would reduce certification costs per service, including direct costs of certification (e.g. auditing and verification) as well as indirect costs of management (e.g. forest inventories specific to particular FES).

However, limited information is available on the feasibility of incorporating FES bundles into the FSC system, which requires some degree of adaptability (e.g., Tuominen et al. 2004, Valentin et al. 2012). Few studies exist on FES certification; those that do propose bundling but do not address feasibility (e.g., Meijaard et al. 2011, 2014). This study aims to address the knowledge gap pragmatically by systematically identifying the support for current FES projects as well as the capacities, preferences, and experiences of FSC stakeholders, which we take as indicators of FSC system adaptability. In particular, the study seeks to reveal supported bundles through analyses of FSC certification bodies' self-assessed capacity to audit FES delivery, FSC enabling partners' preferences in providing training, FSC certificate holders' experience and expectations in managing and selling FES, and how FES projects have targeted FES in the past. All of these are assumed to be strong indicators of the FSC system's adaptability to certifying FES bundles because stakeholder priorities and expectations shape the identification, classification, and valuation of FES (Al-assaf et al. 2014, Deal et al. 2012, Endter-Wada et al. 1998, MA 2005, Martín-López et al. 2011). This study attempts to contribute to analyzing the feasibility of adapting the FSC system to FES management and markets and suggests strategies for managing FES bundles.

\section{LITERATURE REVIEW}

In the ecosystem services literature, the term "bundling" refers to selling multiple services together or combined in a single credit (Deal et al. 2012, Robertson et al. 2014). In contrast, "stacking" refers to selling multiple services associated with the same management practice but accounted for and sold separately. Bundling FES, for example, could entail selling a single credit that combines forest carbon and watershed protection derived from restoration activities in upstream watersheds. Stacking FES would sell the forest carbon and watershed protection as distinct credits. This study adopts the term bundling as a blanket term for various services managed jointly and considers stacking as a particular type of bundling. 
There have been a number of cases of FES bundling around the world. In Oregon, the US, for example, the Counting on The Environment (COTE) standards have been established to trade services of providing wetland, salmonid, upland prairies, or improved water quality in order to motivate landowners to restore multiple FES (Deal et al. 2012). In North Carolina, Neu-Con Bank has sold wetland and nutrient offset credits based on the same conservation action (Fox et al. 2011). In Minnesota, Conservation Marketplace of Minnesota and the American Farmland Trust have initiated a project to trade carbon and water credits (Robertson et al. 2014). In Costa Rica, a national program of payments for environmental service (PES) bundles services of carbon storage, watershed protection, biodiversity conservation, and scenic beauty (Kemkes et al. 2010, Pagiola 2008). In Bolivia, a PES program in Los Negros valley paid farmers for services of protecting bird habitats and upstream watersheds (Asquith et al. 2008, Kemkes et al. 2010). Globally, the development of reducing emissions from deforestation and forest degradation (REDD+) is also discussed in the context of co-benefits, such as biodiversity conservation in addition to forest carbon sequestration (Kanowski et al. 2011). The discussion of REDD+ co-benefits signals a need for better understandings of FES bundles (Robertson et al. 2014).

The motivation to bundle FES derives from a number of expected benefits to forest management and associated markets. Bundling FES could increase forest owners' incomes (Deal et al. 2012, Kemkes et al. 2010, Robertson et al. 2014), enable credit producers to hedge against risk (Robertson et al. 2014), reduce the transaction costs of providing multiple services (Wendland et al. 2010), allow forest owners to access diverse FES markets throughout each individual service in a bundle (Robertson et al. 2014, Wendland et al. 2010), and encourage forest owners to adopt more holistic approaches to management (Deal et al. 2012, Kemkes et al. 2010). These benefits are assumed to be enabling conditions of FES certification. Without these benefits, the economic sustainability of FES certification would be compromised.

Despite the potential benefits mentioned above, certification of FES bundles entails a number of challenges. Most fundamentally, there is insufficient scientific knowledge and associated methodologies to manage and measure delivery of FES in bundles (Robertson et al. 2014, Wendland et al. 2010). Additionally, legal systems often lack a specific mechanism to support governance of FES bundles (Robertson et al. 2014). With FES bundles, the requisite of additionality of service provision becomes more complex and difficult to establish, which requires determination of multiple baselines and development of standardized assessment procedures (Robertson et al. 2014). Delineation of optimal offset caps would be complicated if bundles were to be taken into account (Woodward 2011).

The above challenges compound the more fundamental problems of FES certification, including low market demand, a lack of simple but scientific standards, and an expectation of high certification costs (Meijaard et al. 2011, 2014). Because FES certification is a relatively new practice, empirical research is required to test approaches, methods, and markets in order to assess the feasibility of proposed strategies, such as bundled management and marketing, and to predict potential sources of failure requiring further study or investment prior to implementation.

\section{METHODS}

\section{Analytic framework}

An analytic framework was developed to identify which combinations of FES would be most likely to be supported as bundles in the current FSC system. The framework assumes that supported bundles are those to which the existing system is most adaptable, as reflected in system stakeholders' capacities, preferences, and experience (Figure 1). Four stakeholder groups were taken as representative of the system, including: FSC certification bodies (Group 1), FSC enabling partners (Group 2), FSC certificate holders (Group 3), and FES projects (Group 4). These groups were identified based on their expected key roles in auditing, supporting, and demanding FES certification. Data for Groups 1 to 3 were collected through online surveys. Data for Group 4 were collected from online data and websites of FES projects. An overview of the collected data is presented below in the section entitled "data".

The framework analyzed six indicators (A to F) of FSC stakeholder adaptability. Indicator $A$ is a measure of FSC certification bodies' capacity to audit delivery of FES, which represents the potential supply of FES-auditing services. Indicator $B$ is a measure of FSC enabling partners' preferences to provide FES training programs for forest owners. Indicator $C$ is a measure of FSC certificate holders' expectations of future demand for FES, such as future sales. Indicator $D$ is a measure of FSC certificate holders' experience in protecting FES: i.e., their previous plans or efforts to manage FES. Indicator $E$ is a measure of FSC certificate holders' experience in trading FES. Indicator $F$ is an identification of the specific FES that have previously been selected as targets of FES projects. Indicator A to E were estimated though self-assessment by surveyed stakeholders. Indicator F was estimated based on the researchers' analysis of online data identifying specific services targeted by FES projects.

The framework analyzed system adaptability against three sets of FES: simple, detailed, and mixed sets (Table 1). The simple set, consisting of seven FES variables, was used to survey FSC certificate holders. The groups' response rate was expected to be lower than FSC certification bodies and enabling partners who have strong institutional ties and greater interaction with the FSC. The detailed set, consisting of twelve FES variables, was used to survey FSC certification bodies and enabling partners. The detailed and simple sets were based on three separate surveys designed by the researchers to analyze adaptability of different certification stakeholders in the FSC system. These surveys focused on FES traded in markets for ecosystem services and goods, such as PES schemes, tradable permit programs, as well as ecotourism and NTFPs (Landell-Mills and Porras 2002, MA 2005, Sterner and Coria 2012). The mixed set, consisting of 
FIGURE 1 Analytic framework of the study

\section{Stakeholders of}

FSC expansion to FES Adaptability indicators

FES bundles

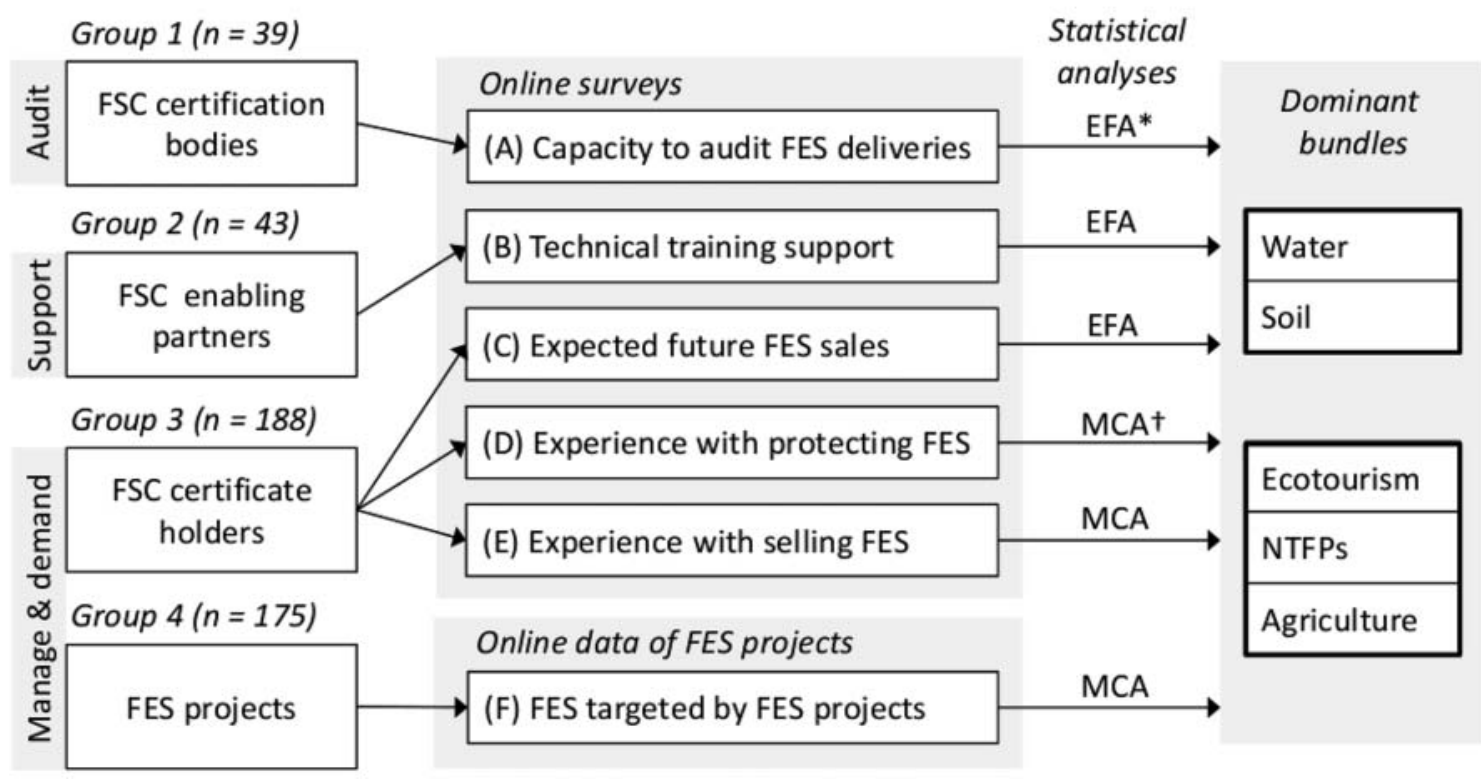

* Explanatory factor analysis for discrete variables

$\uparrow$ Multiple correspondence analysis for dummy variables

TABLE 1 Analytic scope of FES

\begin{tabular}{|c|c|c|c|c|}
\hline Categories & FES & $\begin{array}{c}\text { Detailed } \\
\text { set }^{1}\end{array}$ & $\begin{array}{c}\text { Mixed } \\
\text { set }^{2}\end{array}$ & $\begin{array}{c}\text { Simple } \\
\text { set }^{3}\end{array}$ \\
\hline \multirow[t]{6}{*}{ Regulating services } & Watershed conservation & & $\bullet$ & $\bullet$ \\
\hline & - Water quality & $\bullet$ & & \\
\hline & - Water quantity & $\bullet$ & & \\
\hline & - Water risk & $\bullet$ & $\bullet$ & \\
\hline & Carbon storage & $\bullet$ & $\bullet$ & $\bullet$ \\
\hline & Biodiversity conservation & $\bullet$ & $\bullet$ & $\bullet$ \\
\hline \multirow[t]{4}{*}{ Cultural services } & Ecotourism & & $\bullet$ & $\bullet$ \\
\hline & - Scenic ecotourism & $\bullet$ & & \\
\hline & - Cultural ecotourism & $\bullet$ & $\bullet$ & \\
\hline & - Biodiversity ecotourism & $\bullet$ & & \\
\hline \multirow[t]{2}{*}{ Supporting services } & Soil conservation & $\bullet$ & $\bullet$ & $\bullet$ \\
\hline & - Nutrient conservation & & $\bullet$ & \\
\hline \multirow[t]{4}{*}{ Provisioning services } & Agricultural goods & $\bullet$ & $\bullet$ & $\bullet$ \\
\hline & Non-timber forest products & $\bullet$ & $\bullet$ & $\bullet$ \\
\hline & Timber & $\bullet$ & $\bullet$ & \\
\hline & Total & 12 & 11 & 7 \\
\hline
\end{tabular}

\footnotetext{
${ }^{1}$ For the analyses of certification bodies and FSC enabling partners

${ }^{2}$ For the analysis of FES projects

${ }^{3}$ For the analysis of FSC certificate holders
} 
eleven variables, was based on the secondary data on FES projects. The framework did not consider a combination of sub-categories of the same or closely-related services as FES bundles because these sub-categories were only available in the detailed set. For example, watershed conservation results in at least three FES: water quality improvement, water provision, and water-associated risk reduction, but a bundle of two or more of these three FES were not considered in this study. Moreover, agricultural goods were included in the surveys because some NTFPs (e.g., coffee and tea) overlap with agricultural production systems (MA 2005).

\section{Data}

The data for the study were collected through online surveys and extraction of online data (Table 2 and 3). The online surveys were conducted to estimate system adaptability through self-assessed indicators of capacities, preferences, and experience of FSC certification bodies (Group 1), FSC enabling partners (Group 2), and FSC certificate holders (Group 3) around the world. The surveys were conducted following the Tailored Design Method (Dillman 2011). The online data on prior FES project experience (Group 4) were extracted from online.

FSC certification bodies (Group 1) included those accredited to audit the FSC forest certification scheme. Certification bodies were surveyed from March 12 to 26, 2012. Survey contact information was collected from FSC websites. The survey was conducted in English, as high proficiency in English was expected of this group. Of the 121 contacts, 39 contacts participated in the survey, corresponding to a response rate of $32 \%(=39 / 121)$. Participants represented $64 \%$ of FSC certification bodies. The survey asked participants to evaluate their organizations' engagement with auditing FES against a five-point interval scale: no capacity (1), low capacity (2), medium capacity (3), high capacity (4), and already in business (5).

FSC enabling partners (Group 2) included FSC national network partners, the World Wildlife Fund's Global Forest \& Trade Network (WWF-GFTN), and Greenpeace. FSC national network partners are FSC member organizations around the world (e.g., FSC Chile). They not only promote the current FSC certification but also train forest owners in forest certification. WWF-GFTN and Greenpeace were identified as FSC supporters based on the survey of FSC national network partners. The FSC network partners were surveyed from April 16 to 30, 2012. The WWF-GFTN and Greenpeace were surveyed from July 10 to August 30, 2012. National offices of these organizations were invited to participate in the surveys via email. Survey contact information was collected through organization websites, the above-mentioned national network survey, and personal communications with organization representatives. Surveys were conducted in English as proficiency was expected to be high among the staff of international organizations. Of 117 contacts, 43 contacts responded (19 from the FSC national network partners and 24 from the WWF-GFTN and Greenpeace), resulting in a response rate of $37 \%$ (=43/117). The surveys asked participants to vote for
TABLE 2 Origins of the participants

\begin{tabular}{|c|c|c|}
\hline Origins & No. & Response rate \\
\hline (1) FSC certification bodies & 39 & $32 \%$ \\
\hline International & 16 & \\
\hline Europe & 14 & \\
\hline Latin America & 4 & \\
\hline Asia & 3 & \\
\hline US/Canada & 2 & \\
\hline (2) FSC Enabling partners & 43 & $37 \%$ \\
\hline Europe & 15 & \\
\hline Asia & 10 & \\
\hline Africa & 6 & \\
\hline Latin America & 5 & \\
\hline US/Canada & 3 & \\
\hline International & 3 & \\
\hline Oceania & 1 & \\
\hline (3) FSC Certificate holders & 188 & $16 \%$ \\
\hline Europe & 58 & \\
\hline Latin America & 48 & \\
\hline US/Canada & 35 & \\
\hline Asia & 32 & \\
\hline Africa & 8 & \\
\hline Oceania & 6 & \\
\hline Unknown* & 2 & \\
\hline (4) FES projects & 175 & $\mathrm{n} / \mathrm{a}$ \\
\hline Asia & 57 & \\
\hline Latin America & 41 & \\
\hline US/Canada & 34 & \\
\hline Africa & 28 & \\
\hline Europe & 10 & \\
\hline Oceania & 5 & \\
\hline
\end{tabular}

* Participants skipped socio-demographic questions.

four types of technical training about FES that they would be willing to provide to forest owners. The options included training on legal aspects of FES, quantification of FES, setting monitoring baselines for FES, and monitoring the provision of FES. The number of votes for training for each FES was counted. The range of the counted values was from 0 (no training) to 4 (four sessions of training). The study assumed that the higher the counted value, the stronger the preference to provide the indicated types of training.

FSC forest management certificate holders (Group 3) represented FSC's current market for forest certification, as well as potential sellers of FES. Many of these certificate holders owned plantation forests which are also known to deliver various FES (Bauhus et al. 2010). Some of the 
TABLE 3 Descriptive statistics of the data

\begin{tabular}{|c|c|c|c|c|c|c|c|c|c|c|c|c|}
\hline \multirow[t]{2}{*}{ FES } & \multicolumn{2}{|c|}{$\begin{array}{l}\text { Indicator } A: \\
\text { auditing }\end{array}$} & \multicolumn{2}{|c|}{$\begin{array}{l}\text { Indicator } B: \\
\text { training }\end{array}$} & \multicolumn{2}{|c|}{$\begin{array}{l}\text { Indicator } C \text { : } \\
\text { future sales }\end{array}$} & \multicolumn{2}{|c|}{$\begin{array}{c}\text { Indicator } D: \\
\text { protection experience }\end{array}$} & \multicolumn{2}{|c|}{$\begin{array}{c}\text { Indicator } E \text { : } \\
\text { selling experience }\end{array}$} & \multicolumn{2}{|c|}{$\begin{array}{c}\text { Indicator } F \text { : } \\
\text { project targets }\end{array}$} \\
\hline & $\mathbf{M}$ & SD & $\mathbf{M}$ & SD & $\mathbf{M}$ & SD & $\mathbf{M}$ & SD & $\mathbf{M}$ & SD & $\mathbf{M}$ & SD \\
\hline Water & & & & & 2.65 & 1.57 & 0.75 & 0.43 & 0.17 & 0.38 & 0.69 & 0.46 \\
\hline - Quality & 2.75 & 1.45 & 2.70 & 1.81 & & & & & & & & \\
\hline - Quantity & 2.62 & 1.44 & 2.42 & 1.74 & & & & & & & & \\
\hline - Risk & 2.64 & 1.44 & 2.56 & 1.76 & & & & & & & 0.25 & 0.44 \\
\hline Carbon & 3.26 & 1.46 & 3.12 & 1.72 & 3.25 & 1.53 & 0.39 & 0.49 & 0.43 & 0.50 & 0.17 & 0.37 \\
\hline Biodiversity & 3.51 & 1.35 & 3.81 & 1.52 & 3.05 & 1.61 & 0.91 & 0.28 & 0.31 & 0.46 & 0.26 & 0.44 \\
\hline Ecotourism & & & & & 2.77 & 1.54 & 0.29 & 0.45 & 0.29 & 0.46 & 0.49 & 0.50 \\
\hline - Culture & 2.90 & 1.33 & 1.98 & 1.52 & & & & & & & 0.30 & 0.46 \\
\hline - Scenic & 2.92 & 1.35 & 2.09 & 1.57 & & & & & & & & \\
\hline - Biodiversity & 3.18 & 1.35 & 2.61 & 1.72 & & & & & & & & \\
\hline Soil & 3.39 & 1.46 & 3.07 & 1.75 & 2.27 & 1.43 & 0.62 & 0.49 & 0.05 & 0.23 & 0.25 & 0.44 \\
\hline - Nutrient & & & & & & & & & & & 0.11 & 0.31 \\
\hline Agriculture & 3.90 & 1.45 & 2.02 & 1.52 & 1.69 & 1.18 & 0.08 & 0.26 & 0.11 & 0.31 & 0.34 & 0.47 \\
\hline NTFPs & 4.10 & 1.31 & 3.14 & 1.73 & 2.53 & 1.40 & 0.38 & 0.49 & 0.33 & 0.47 & 0.17 & 0.37 \\
\hline Timber & 4.54 & 1.14 & 4.09 & 1.34 & & & & & & & 0.18 & 0.39 \\
\hline
\end{tabular}

(M: mean / SD: standard deviation)

certificate holders also came from national park systems where natural forests are dominant. FSC certificate holders were surveyed from July 9 to August 3, 2012. Contact information was obtained from the FSC. Since forest owners were expected to have a low response rate and low English proficiency, the survey was conducted in multiple languages, including Chinese, English, French, Indonesian, Japanese, Korean, Portuguese, Spanish, and Vietnamese. The survey also provided examples to ensure a common understanding of FES definitions. Of 1216 contacts, 58 contacts were not valid. 188 of the remaining contacts participated in the survey, corresponding to a response rate of $16 \%$ (=188/1158). The survey asked FSC certificate holders to rate their experience in management and sales of FES in certified forests. Responses were coded as 0 (having no experience) and 1 (having experience). They were also asked to rate their expectations for future FES sales from the forests, using a five-point interval scale: low (1), low-medium (2), medium (3), medium high (4), and high (5).

FES projects (Group 4) included potential stakeholders of FES certification from the FSC's external market. They included integrated conservation and development projects (ICDP) and PES schemes, whose objectives are to manage or trade FES. FES projects were examined based on available online data. The data were mainly obtained from the database of the Integrated Valuation of Environmental Services and Tradeoffs (InVEST) project ${ }^{2}$ which included information on 159 FES projects classified as ICDP and/or PES projects. Using the mixed set of FES (Table 1), we coded FES of these projects as 1 when the projects aimed to manage these FES and as 0 when the FES were not included in the project objectives. In addition to the InVEST database, an additional 16 PES projects were included into the secondary data identified by the literature, including Rewarding Upland Poor for the Environmental Services (RUPES) ${ }^{3}$ and Pro-poor Rewards for Environmental Services in Africa (PRESA) ${ }^{4}$.

\section{Statistical analyses}

The study analyzed the appearance of multiple FES (or FES bundles) against the six indicators (A to F) of system adaptability by employing exploratory factor analysis (EFA) and multiple correspondence analysis (MCA) (Table 4). Both EFA and MCA are statistical techniques used to identify relationships among variables or samples in reduced dimensions (Greenacre \& Blasius 2006, Husson et al. 2016, Thompson 2004). EFA was applied to Indicators A, B, and C. MCA was applied to Indicators D, E, and F. Computations were performed using the statistical software R (3.2.5) and R packages psych (Revelle 2015) and FactoMineR (Husson et al. 2016). 
TABLE 4 Statistical methods and data structures

\begin{tabular}{lccc}
\hline \multicolumn{1}{c}{ Adaptability indicators } & Statistical method & Variable type & Sample and variable ratio * \\
\hline A) Auditing FES delivery & EFA & Interval & $3: 1(=39: 12)$ \\
\hline B) Technical training support & EFA & Interval & $4: 1(=43: 12)$ \\
\hline C) Expected future FES sales & EFA & Interval & $27: 1(=188: 7)$ \\
\hline D) Experience with protecting FES & MCA & Dummy & $27: 1(=188: 7)$ \\
\hline E) Experience with selling FES & MCA & Dummy & $27: 1(=188: 7)$ \\
\hline F) FES targeted by projects & MCA & Dummy & $16: 1(=175: 11)$ \\
\hline
\end{tabular}

* Ratios are rounded up as integers.

$E F A$ was applied to the five-point interval data (e.g., low = 1 to high = 5). EFA is a descriptive multivariate technique used to discover coherent subsets (or factors) in observed variables by detecting correlation patterns (Thompson 2004). EFA has been applied in studies of psychology and health, as well as forest certification (Araujo et al. 2009, Litwin et al. 1998, Thompson 2004). Various guidelines exist on minimum sample sizes (100 to 1000 ) and the minimum ratio of sample size to the number of variables $(3: 1$ to $10: 1)$ for factor analysis although such guidelines are also considered to lack empirical validity (MacCallum et al. 1999, Osborne \& Costello 2004, Thompson 2004). Moreover, results of factor analysis are considered stable if they produce high degrees of communality (>0.6) (Thompson 2004, MacCallum et al. 1999). Therefore, although the sample sizes of certification bodies (39) and FSC enabling partners (43) were considered to be low for the purpose of conducting confirmatory factor analysis (CFA), EFA was applicable to these data because the data's sample to variable ratio met the ratio of at least 3:1; results reached high degrees of communality $(>0.6)$; and the survey of certification bodies represented $64 \%$ of certification bodies accredited by FSC. In this study, EFA was based on either varimax or quatimax rotation. Factor extraction was based on eigenvalues higher than 1, following the KaiserGuttman criterion (Guttman 1954, Kaiser 1960). Extracted factors represent an amount of information in the data, or variance (Thompson 2004). Factor loadings of FES variables describe the relationships between factors and FES.

$M C A$ was applied to datasets of binary values (e.g., $1=$ experienced and $0=$ not experienced). Like EFA, MCA is used in descriptive multivariate statistics to reduce the dimensions of data matrices (Greenacre \& Blasius 2006, Hoffman \& De Leeuw 1992, Le Roux \& Rouanet 2010). However, while EFA is used for analyzing quantitative variables, MCA is used for analyzing qualitative variables (Husson et al. 2011, Le Roux \& Rouanet 2010, Greenacre \& Blasius 2006). MCA has been applied in studies of medical, psychology, and marketing research (Greenacre \& Blasius 2006, Hoffman \& De Leeuw 1992, Tenenhaus \& Young 1985). In this study, MCA was calculated based on an indicative matrix. Dimension extraction was based on the average inertia of each active category, which is equivalent to Kaiser's rule in EFA (Di Franco 2016). To interpret the MCA results, discrimination measures of the FES variables were used. Interpreted as squared factor loadings, discrimination measures refer to correlation ratios between individual samples and the categorical variables (Hoffman and De Leeuw 1992, Husson et al. 2011). The study also applied two-dimensional maps to analyze their relationships following a dominant approach to interpreting MCA results (Greenacre \& Blasius 2006, Husson et al. 2011). On the map, for example, two variables close to each other indicate their close relationships (Husson et al. 2011).

\section{RESULTS}

\section{Group 1: FSC certification bodies}

EFA results from certification bodies' capacity to audit delivery of FES revealed no FES bundles (Indicator A in Table 5). The EFA employed varimax rotation. Three factors were identified, explaining $80.4 \%$ of the data variance. Despite the high communality estimate, none of these factors were considered as FES bundles since each group consisted of sub-categories of the same categories of FES. Factor 1 was comprised of a grouping of watershed conservation services. Factor 2 was comprised of provision of several ecosystem goods which included agricultural goods, NTFPs, and timber. Factor 3 loaded only the sub-categories of ecotourism.

\section{Group 2: FSC enabling partners}

EFA results from FSC enabling partners' support for FES management training revealed three FES bundles (Indicator $\mathrm{B}$ in Table 5). The EFA used varimax rotation. Three factors were identified, explaining $69.5 \%$ of the data variance. Factor 1 revealed a bundle of water quality, water quantity, water risk, and soil conservation. Factor 2 identified a bundle of scenic beauty experience for ecotourism, cultural experience for ecotourism, biodiversity experience for ecotourism, and agricultural goods. Factor 3 revealed a bundle of carbon storage, biodiversity conservation, and timber. This factor was only observed in data from FSC enabling partners, combining regulating services (carbon and biodiversity) and a provisioning service (timber). 
TABLE 5 Results from FSC certification bodies (Indicator A) and FSC enabling partners (Indicator B)

\begin{tabular}{|c|c|c|c|c|c|c|}
\hline \multirow{2}{*}{ FES } & \multicolumn{3}{|c|}{$\begin{array}{c}\text { Indicator A: } \\
\text { Auditing FES deliveries (EFA) }\end{array}$} & \multicolumn{3}{|c|}{$\begin{array}{c}\text { Indicator } B: \\
\text { Technical training support (EFA) }\end{array}$} \\
\hline & Factor & Factor 2 & Factor 3 & Factor 1 & Factor 2 & Factor 3 \\
\hline Water quality & 0.95 & 0.14 & 0.18 & 0.85 & 0.23 & 0.16 \\
\hline Water quantity & 0.84 & 0.06 & 0.33 & 0.82 & 0.30 & 0.11 \\
\hline Water risk & 0.98 & 0.11 & 0.11 & 0.83 & 0.26 & 0.22 \\
\hline Carbon & 0.62 & 0.36 & 0.23 & 0.25 & -0.02 & 0.74 \\
\hline Biodiversity & 0.46 & 0.48 & 0.52 & 0.08 & 0.43 & 0.71 \\
\hline Ecotour.scenic & 0.21 & 0.13 & 0.95 & 0.13 & 0.88 & -0.06 \\
\hline Ecotour.culture & 0.16 & 0.16 & 0.97 & 0.34 & 0.82 & -0.08 \\
\hline Ecotour.biodiversity & 0.36 & 0.40 & 0.63 & 0.19 & 0.72 & 0.30 \\
\hline Soil & 0.48 & 0.65 & 0.25 & 0.73 & 0.12 & 0.46 \\
\hline Agriculture & 0.29 & 0.85 & 0.26 & 0.44 & 0.63 & -0.17 \\
\hline NTFPs & 0.07 & 0.91 & 0.14 & 0.30 & 0.44 & 0.41 \\
\hline Timber & 0.02 & 0.71 & 0.07 & 0.11 & -0.27 & 0.72 \\
\hline Variance (\%) & 30.8 & 25.6 & 24.0 & 26.2 & 25.4 & 17.9 \\
\hline Cut value & $>0.8$ & $>0.7$ & $>0.9$ & $>0.7$ & $>0.6$ & $>0.7$ \\
\hline
\end{tabular}

The results demonstrate factor loadings.

\section{Group 3: FSC certificate holders}

EFA results of FSC certificate holders' expectations for future FES sales revealed one FES bundle (Indicator C in Table 6). The EFA employed quatimax rotation. Two factors were identified, explaining $61.1 \%$ of the data variance. Factor 1 revealed a bundle of watershed conservation, biodiversity conservation, ecotourism, and soil conservation, i.e., a bundle of regulating, cultural, and supporting services. Factor 2 loaded agricultural goods and NTFPs. However, these are sub-categories of the same category of FES (provision of ecosystem goods) and, consequently, were not considered as a potential FES bundle.

MCA results from FSC certificate holders' experience of protecting FES revealed three FES bundles (Indicator D in Table 6). Two dimensions were identified, explaining $45.1 \%$ of the data variance (or of the total inertia). Dimension 1 revealed a bundle of soil, water, and biodiversity. Dimension

TABLE 6 Results from FSC certificate holders (Indicator C, D, and E)

\begin{tabular}{|c|c|c|c|c|c|c|c|}
\hline \multirow[t]{2}{*}{ FES } & \multicolumn{2}{|c|}{$\begin{array}{c}\text { Indicator } C \text { : } \\
\text { Expected future FES } \\
\text { sales (EFA) }\end{array}$} & \multicolumn{2}{|c|}{$\begin{array}{c}\text { Indicator } D: \\
\text { Experience with } \\
\text { protecting FES (MCA) }\end{array}$} & \multicolumn{3}{|c|}{$\begin{array}{c}\text { Indicator } E \text { : } \\
\text { Experience with } \\
\text { selling FES (MCA) }\end{array}$} \\
\hline & Factor 1 & Factor 2 & Dim 1 & $\operatorname{Dim} 2$ & $\operatorname{Dim} 1$ & $\operatorname{Dim} 2$ & $\operatorname{Dim} 3$ \\
\hline Water & 0.74 & -0.46 & 0.45 & 0.00 & 0.67 & 0.00 & 0.00 \\
\hline Carbon & 0.51 & -0.15 & 0.16 & 0.47 & 0.07 & 0.36 & 0.17 \\
\hline Biodiversity & 0.80 & -0.31 & 0.32 & 0.03 & 0.64 & 0.01 & 0.06 \\
\hline Ecotourism & 0.72 & 0.01 & 0.23 & 0.12 & 0.06 & 0.34 & 0.20 \\
\hline Soil & 0.79 & 0.00 & 0.58 & 0.00 & 0.48 & 0.01 & 0.09 \\
\hline Agriculture & 0.47 & 0.68 & 0.10 & 0.34 & 0.01 & 0.16 & 0.58 \\
\hline NTFPs & 0.52 & 0.64 & 0.29 & 0.07 & 0.00 & 0.59 & 0.04 \\
\hline Variance (\%) & 44.0 & 17.1 & 30.3 & 14.8 & 27.6 & 21.1 & 16.3 \\
\hline Cut value & $>0.7$ & $>0.6$ & $>0.30$ & $>0.30$ & $>0.40$ & $>0.30$ & $>0.30$ \\
\hline
\end{tabular}

EFA results demonstrate factor loadings.

MCA results demonstrate discrimination measures. 
FIGURE 2 MCA result from FSC certificate holders (Indicator D: experience with protecting FES)

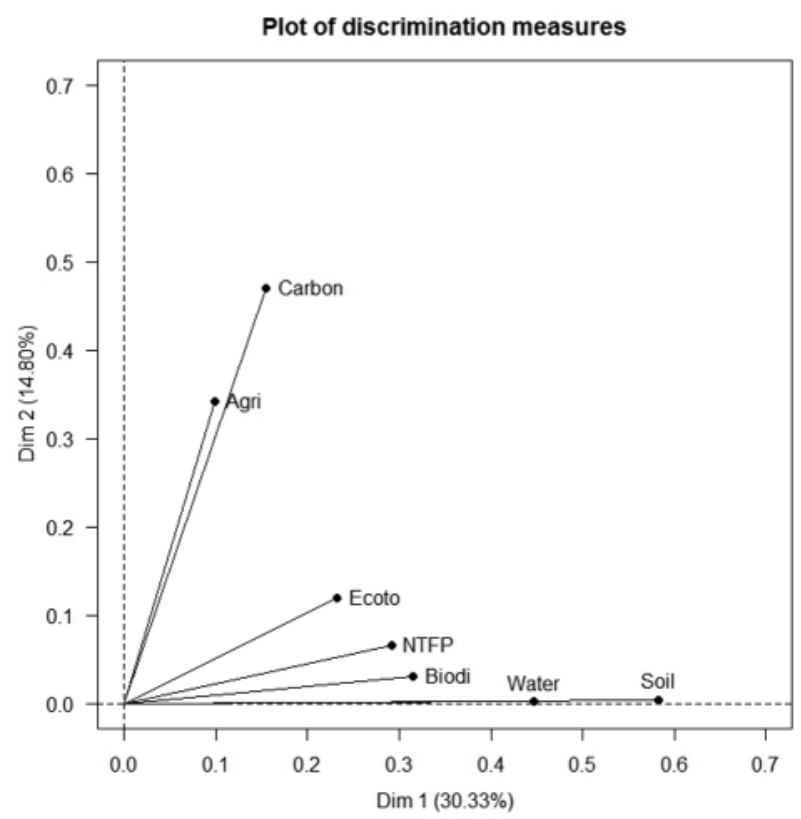

2 identified a bundle of carbon and agriculture. On the two-dimensional map (Figure 2), soil, water, and biodiversity appeared close to each other. Carbon and agriculture demonstrated their relationship. Although not meaningfully related to Dimension 1, ecotourism and NTFPs demonstrated their relationship based on their close positions on the plot; thus, they were also considered as a FES bundle in the analysis.

MCA results from FSC certificate holders' experience of selling FES revealed two FES bundles (Indicator E in Table 6). Three dimensions were identified, explaining $64.9 \%$ of the total inertia. Dimension 1 revealed a bundle of soil, water, and biodiversity. Dimension 2 identified a bundle of NTFPs, carbon, and ecotourism. Dimension 3 was only related to agriculture, failing to demonstrate any bundle. In Figure 3, although agriculture was highly related to Dimension 3, the plot illustrates that agriculture is still connected to the FES bundle of Dimension 2.

\section{Group 4: FES projects}

MCA results of FES targeted by projects revealed two FES bundles (Indicator F in Table 7 and Figure 4). Three dimensions were identified explaining $52.7 \%$ of the total inertia. Dimension 1 revealed a bundle of agriculture, cultural ecotourism, timber, and NTFPs. These services represent cultural and provisioning services relevant to major economic activities in forestry. Dimension 2 identified a bundle of water, water risk, and soil services. These FES are relevant to environmental managements. Dimension 3 was related to carbon only and failed to produce any likely bundle.

\section{Dominant FES bundles}

Two FES bundles were supported across multiple indicators of FSC system adaptability, and we therefore consider them
FIGURE 3 MCA result from FSC certificate holders (Indicator E: Experience with selling FES)

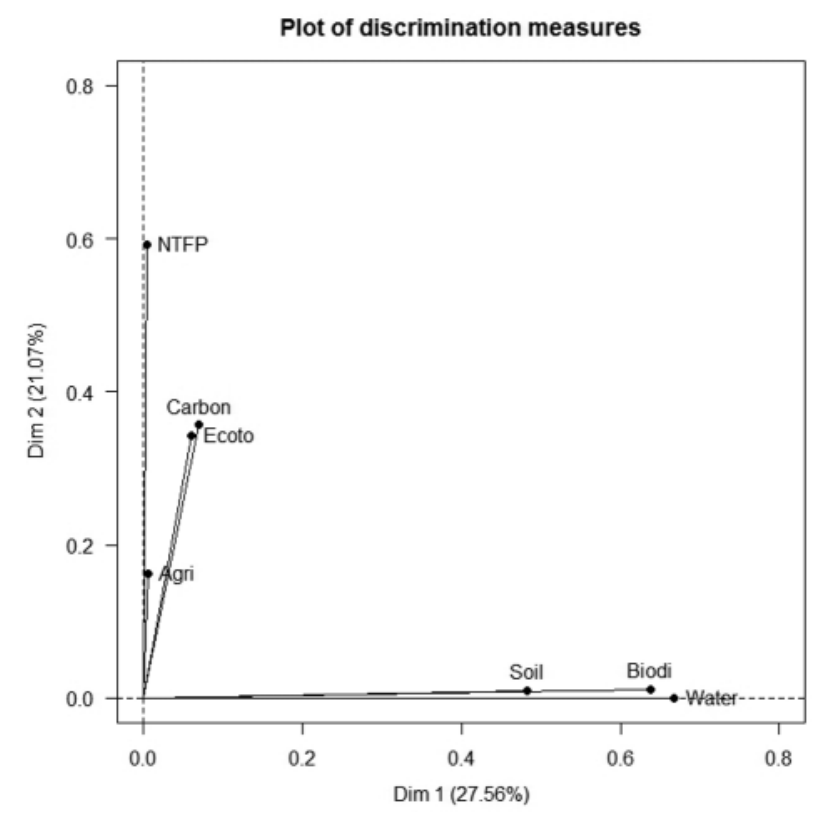

TABLE 7 Results from FES projects (Indicator F)

\begin{tabular}{lccc}
\hline \multirow{2}{*}{ FES } & \multicolumn{3}{c}{ Indicator F: } \\
& FES targeted by the projects (MCA) \\
\cline { 2 - 4 } & Dim 1 & Dim 2 & Dim 3 \\
\hline Water & 0.00 & $\mathbf{0 . 4 9}$ & 0.01 \\
\hline Water risk & 0.00 & $\mathbf{0 . 4 1}$ & 0.02 \\
\hline Carbon & 0.02 & 0.02 & $\mathbf{0 . 4 3}$ \\
\hline Biodiversity & 0.28 & 0.12 & 0.13 \\
\hline Ecotourism & 0.19 & 0.00 & 0.02 \\
\hline Ecotour.culture & $\mathbf{0 . 6 1}$ & 0.04 & 0.05 \\
\hline Soil & 0.15 & $\mathbf{0 . 3 9}$ & 0.02 \\
\hline Nutrient & 0.10 & 0.27 & 0.14 \\
\hline Agriculture & $\mathbf{0 . 6 2}$ & 0.03 & 0.01 \\
\hline NTFP & $\mathbf{0 . 3 9}$ & 0.00 & 0.27 \\
\hline Timber & $\mathbf{0 . 4 1}$ & 0.00 & 0.17 \\
\hline Variance (\%) & 25.2 & 16.1 & 11.5 \\
\hline Cut values & $>30$ & $>30$ & $>40$ \\
\hline
\end{tabular}

The results demonstrate discrimination measures.

to be dominant, i.e. likely to be most feasible under current conditions (Table 8). Bundle 1 included watershed and soil conservation services and was supported by Indicators B, C, $\mathrm{D}$, E, and F. Bundle 2 included cultural ecotourism with NTFPs or agricultural goods and was supported by Indicators B, D, E, and F. Although NTFPs and agricultural goods were separated in the surveys, these services share many products particularly in the context of forests (e.g., coffee); thus, the study treated them as similar kinds of FES, as discussed in the 
FIGURE 4 MCA result from FES projects (Indicator F: FES targeted by the projects)

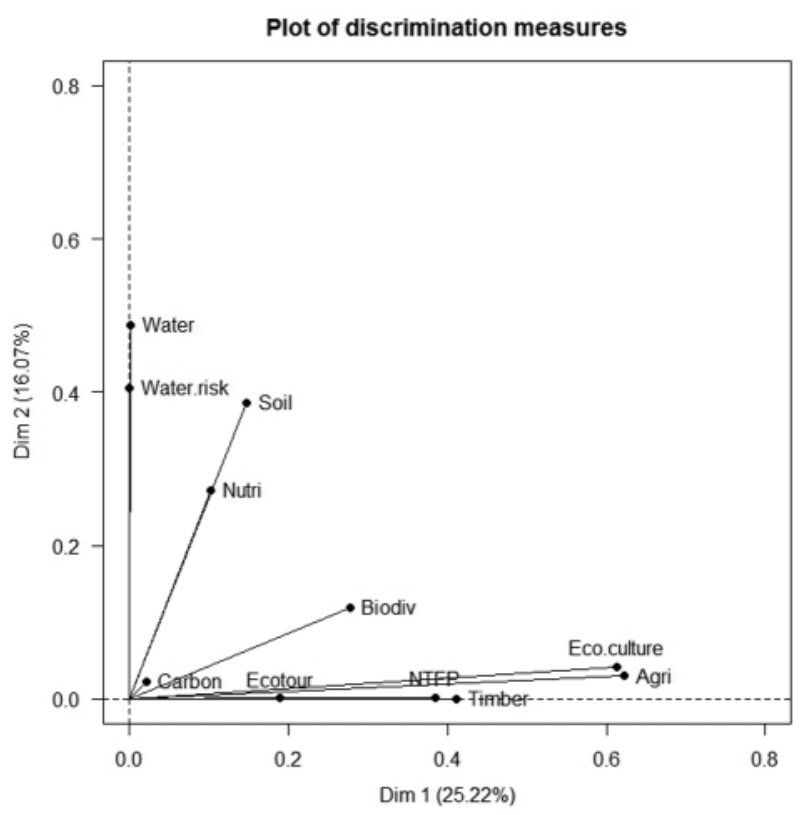

methods and Group 1 results. In addition to Bundle 1 and 2, other bundles were identified from the analyses. However, they were either supported by a single indicator of the adaptability (e.g., carbon, biodiversity, and timber in Indicator B) or represented bundles of closely related FES (e.g., scenic and biodiversity ecotourism in Indicator A). Therefore, these bundles were not considered dominant.

\section{DISCUSSION}

The study identified two dominant bundles of FES across multiple indicators of FSC system adaptability. Although there is no certification scheme for these FES bundles yet, the bundles exist in conventional FES management, such as watershed management (Bundle 1) and rural tourism (Bundle 2).

The services in Bundle 1 are associated with strategies to manage water quality (Table 9). Many watershed management projects control soil erosion and sediment in order to improve water quality in watersheds and streams (Bennett et al. 2009, Kerr 2002, Landell-Mills \& Porras 2002, Raudsepp-Hearne et al. 2010). According to Bennett et al. (2009), the two services in Bundle 1 have a "unidirectional interaction" since they are in a cause-and-effect relationship, where soil erosion decreases water quality. Watershed services are managed by some standards. For example, there have been efforts to develop and apply a standard of watershed management, notably the Alliance for Water Stewardship (AWS 2013). In the US, water quality standards are designed to certify water quality credits even though they belong to mandatory FES markets (or water quality trading programs) (EPA 2004). The FSC's international principles and criteria also require water and soil management (FSC 2012, Stupak et al. 2011), but these FSC requirements are too general to measure watershed services such as water quality or quantity (van Dam et al. 2010). To certify Bundle 1, therefore, FSC would need to develop additional certification system such as a new standard for the bundle, verification procedure, and system to deliver information on certified bundle credits to FES markets (e.g., a public database for certified credits). Furthermore, the integration of Bundle 1 into certification requires overcoming challenges involved with watershed management ranging from the technical difficulties of measuring and monitoring watershed functions (IUCN \& WBCSD 2012, Meijaard et al. 2011) to complex socioeconomic issues affecting the engagement of watershed stakeholders (Hanemann 2006).

The services in Bundle 2 are associated with the development of rural tourism and in particular, agritourism, which has long been popular in Europe and Canada (Dernoi 1983, MacDonald and Jolliffe 2003, Nickerson et al. 2001, Sharpley \& Vass 2006). Agritourism diversifies farmers' income sources by attracting tourists interested in experiencing the rural and farm lifestyle. The services in Bundle 2 have "no direction of interaction" according to Bennett et al. (2009). Each service is already certified by many certification schemes specialized in ecotourism, NTFPs, organic products, and fair trade certification schemes (Black \& Crabtree 2007, Cashore et al. 2006, Kozak et al. 2004, Shanley et al. 2008). Some NTFPs, such as Brazil nuts, have been already certified under FSC certification (Shanley et al. 2008). To date, however, none of these certification schemes explicitly certify

TABLE 8 Two dominant FES bundles from EFA and MCA

\begin{tabular}{lccl}
\hline Adaptability indicators & Method & $\begin{array}{c}\text { Bundle 1 } \\
\text { water / soil }\end{array}$ & ecotourism / NTFPs or agriculture \\
\hline A) Auditing FES delivery & EFA & Not observed & Not observed \\
\hline B) Technical training support & EFA & water / soil & ecotourism / agriculture \\
\hline C) Expected future FES sales & EFA & water / soil & Not observed \\
\hline D) Experience with protecting FES & MCA & water / soil & ecotourism / NTFPs \\
\hline E) Experience with selling FES & MCA & water / soil & ecotourism / NTFPs \\
\hline F) FES targeted by projects & MCA & water / soil & ecotourism / NTFPs \& agriculture \\
\hline
\end{tabular}


TABLE 9 Two dominant FES bundles from FSC stakeholder adaptability

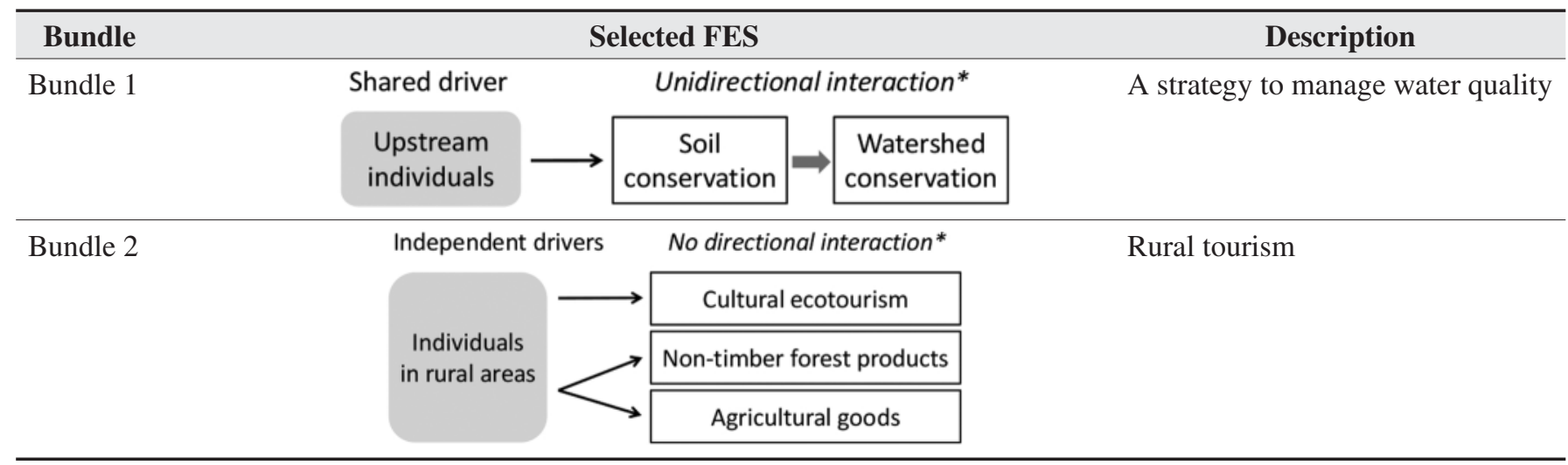

"The framework of FES relationship directions was adapted from Bennett et al. (2009).

Bundle 2. FSC stakeholders are less adapted to deal with functions related to certification of ecotourism and agricultural products in comparison to other FES such as biodiversity and NTFPs (Jaung et al. 2016). To certify Bundle 2, therefore, the FSC system would need to be equipped with a new certification system, including additional standard for the bundle and a chain-of-custody certification system to ensure that supply chains of NTFPs and agricultural goods are maintained from source to market. The FSC system would also need to improve stakeholder capacity to adapt to the individual services in Bundle 2.

By identifying potential FES bundles likely to be supported by the current FSC system, the findings of this study contribute to assessing the feasibility of a potentially new certification option and inform future studies on FES certification. These bundles are derived from socio-economic aspects of FES bundles and certification-oriented FES management. This socio-economic domain plays significant roles in valuing, managing, and trading FES (Al-assaf et al. 2014, Deal et al. 2012, Endter-Wada et al. 1998, MA 2005, MartínLópez et al. 2012) and, therefore, in the incorporation of FES bundles into the certification process for FES based on the FSC system. Although focusing on certification, moreover, the study findings are potentially applicable to general FES management, since Bundle 1 and 2 were supported by FSC certificate holders and FES projects (Table 8).

Certainly, challenges emerge from our investigation into the feasibility of certification of particular FES bundles. First, the auditing capacity of certification bodies would need to be improved to make both bundles functional because they appear to be overly specialized within the same type of FES (Table 5). Certification bodies are a key component of certification system because third-party auditing is central to building the credibility upon which voluntary certification is grounded (Nussbaum and Simula 2013). Second, the feasibility of developing standards for these FES bundles is unknown and would be challenged by limited scientific knowledge and the complexity of FES management (MA 2005, Meijaard et al. 2011, 2014). Third, successful certification of these bundles would be dependent on demand for the individual FES among forest owners and service buyers (e.g., buyers of water and soil service credits). Lack of market demand would be a challenge in implementing voluntary certification of these FES (Meijaard et al. 2011, 2014). However, the level of demand for the individual FES in Bundle 1 and 2 is, as yet, uncertain.

Last but not least, the study has its limitations, signalling a need for further inquiry. First, the study is based on selfassessed adaptability of certification stakeholders measured by online surveys. In order to obtain more accurate measurements, a standardized test would be required based on face-toface surveys. Second, although dominant, Bundle 1 and 2 were not supported by all entire stakeholder groups. The low adaptability of the non-supported stakeholders (e.g., certification bodies) should be considered in analyzing potential integration of Bundle 1 and 2 into certification. Third, some bundles were only reported by one stakeholder group and therefore they were excluded from further analysis; bundles of interest to particular certification stakeholders should be selected for specific study. Fourth, the study examines a limited number of stakeholder groups. The scope of FES certification stakeholders is broad, including FES market stakeholders. FSC stakeholders are also changeable over time. Thus, further stakeholder groups need to be examined in order to analyze the feasibility of FES certification and its potential to incorporate FES bundles.

\section{CONCLUSIONS}

The study identifies two potential bundles of FES through analyses of adaptability of FSC certification bodies, enabling partners, certificate holders, and FES projects. Bundle 1 included services of watershed and soil conservation. These services are in fact commonly produced together by water projects as a watershed management strategy. Bundle 2 included services supporting agricultural goods, non-timber forest products, and cultural ecotourism. Traditional rural tourism in some areas constitutes a ready market for such a combination of services. These findings contribute to assessing the feasibility of expanding the FSC system to multiple FES (or bundles) by determining which bundles would 
already be most supported by the current system's adaptability. The study is limited to the social domain, and the FSC's potential expansion faces a number of unaddressed challenges. These results do not preclude the development of other bundles, for which system infrastructures and markets might be developed given interest and investment. Regardless, future studies are required to analyze market demand for certified FES bundles and the feasibility of developing certification standards for FES bundles and their chains-ofcustody; other studies might be designed to assess particular FES bundles of interest to certification stakeholders beyond Bundles 1 and 2.

\section{ACKNOWLEDGEMENT}

The authors thank the Forest Stewardship Council (FSC), FSC network partners, World Wildlife Fund Indonesia, and WWF Global Forest \& Trade Network for their support of this research. We also give special thanks to all the survey participants. The research was funded by the Global Environmental Facility through the United Nations Environment Programme, by the University of British Columbia through a Faculty of Forestry Strategic Recruitment Fellowships, and by donors to the CGIAR Consortium Research Program on Forests, Trees, and Agroforestry.

\section{REFERENCES}

AL-ASSAF, A., NAWASH, O. and OMARI, M. 2014. Identifying forest ecosystem services through socio-ecological bundles: a case study from northern Jordan. International Journal of Sustainable Development \& World Ecology 21(4): 314-321.

ARAUJO, M., KANT, S. and COUTO, L. 2009. Why Brazilian companies are certifying their forests? Forest Policy and Economics 11: 579-585.

ASQUITH, N.M., VARGAS, M.T. and WUNDER, S. 2008. Selling two environmental services: In-kind payments for bird habitat and watershed protection in Los Negros, Bolivia. Ecological Economics 65(4): 675-684.

AULD, G. and BULL, G.Q. 2003. The institutional design of forest certification standards initiatives and its influence on the role of science: the case of forest genetic resources. Journal of Environmental Management 69(1): 47-62.

AWS (Alliance for Water Stewardship). 2013. The AWS International Water Stewardship Standard: Beta version for stakeholder input and field testing, Version 04.03.2013.

BASS, S. and SIMULA, M. 1999. Independent Certification/ Verification of Forest Management. The World Bank and WWF Alliance Workshop. Washington, D.C.

BAUHUS, J., VAN DER MEER, P. and KANNINEN, M. 2010. Ecosystem Goods and Services from Plantation Forests. London, Earthscan.

BENNETT, E.M., PETERSON, G.D. and GORDON, L.J. 2009. Understanding relationships among multiple ecosystem services. Ecology Letters 12(12): 1394-1404.
BLACK, R. and CRABTREE, A. 2007. Quality Assurance and Certification in Ecotourism. Cambridge, CABI Pub.

CASHORE, B., GALE, F., MEIDINGER, E. and NEWSOM, D. 2006. Confronting Sustainability: Forest Certification in Developing and Transitioning Countries. New Haven, Yale School of Forestry \& Environmental Studies.

CERUTTI, P.O., TACCONI, L., NASI, R. and LESCUYER, G. 2011. Legal vs. certified timber: Preliminary impacts of forest certification in Cameroon. Forest Policy and Economics 13(3): 184-190.

CHE, D. 2006. Developing ecotourism in First World, resource-dependent areas. Geoforum 37(2): 212-226.

DEAL, R.L., COCHRAN, B. and LAROCCO, G. 2012. Bundling of ecosystem services to increase forestland value and enhance sustainable forest management. Forest Policy and Economics 17(0): 69-76.

DERNOI, L.A. 1983. Farm tourism in Europe. Tourism Management 4(3): 155-166.

DI FRANCO, G. 2016. Multiple correspondence analysis: one only or several techniques? Quality \& Quantity 50(3): 1299-1315.

DIAS, F.S., BUGALHO, M.N., RODRÍGUEZ-GONZÁLEZ, P.M., ALBUQUERQUE, A. and CERDEIRA, J.O. 2015. Effects of forest certification on the ecological condition of Mediterranean streams. Journal of Applied Ecology 52(1): 190-198.

DILLMAN, D.A. 2011. Mail and Internet surveys: The tailored design method--2007 Update with new Internet, visual, and mixed-mode guide, John Wiley \& Sons.

DURST, P., MCKENZIE, P.J., BROWN, C.L. and APPANAH, S. 2006. Challenges facing certification and eco-labelling of forest products in developing countries. International Forestry Review 8(2): 193-200.

ELLIOTT, C. and SCHLAEPFER, R. 2001. Understanding forest certification using the Advocacy Coalition Framework. Forest Policy and Economics 2(3-4): 257-266.

ENDTER-WADA, J., BLAHNA, D., KRANNICH, R. and BRUNSON, M. 1998. A framework for understanding social science contributions to ecosystem management. Ecological Applications 8(3): 891-904.

EPA (Environmental Protection Agency). 2004. Water Quality Trading Assessment Handbook: Can Water Quality Trading Advance Your Watershed's Goals? Washington, DC.

FOX, J., GARDNER, R.C. and MAKI, T. 2011. Stacking Opportunities and Risks in Environmental Credit Markets. Environmental Law Reporter, News \& Analysis 41(2): 10121-10125.

FSC (The Forest Stewardship Council). 2012. FSC Principles and Criteria for Forest Stewardship (FSC-STD-01-001 V5-0 D5-0 EN). Bonn.

GAN, J. and CASHORE, B. 2013. Opportunities and Challenges for Integrating Bioenergy into Sustainable Forest Management Certification Programs. Journal of Forestry 111(1): 11-16.

GR $\overline{E E N A C R E, ~ M . ~ a n d ~ B L A S I U S, ~ J . ~ 2006 . ~ M u l t i p l e ~ c o r r e-~}$ spondence analysis and related methods, CRC Press. 
GRISCOM, B., ELLIS, P. and PUTZ, F.E. 2014. Carbon emissions performance of commercial logging in East Kalimantan, Indonesia. Global Change Biology 20(3): 923-937.

GUTTMAN, L. 1954. Some necessary conditions for common-factor analysis. Psychometrika 19(2): 149-161.

HANEMANN, M.W. 2006. The Economic Conception of Water. Water Crisis: Myth or Reality? P.P. Rogers, M.R. Llamas and L. Martinez-Cortina. London; New York, Taylor \& Francis: 61-91.

HOFFMAN, D.L. and DE LEEUW, J. 1992. Interpreting multiple correspondence analysis as a multidimensional scaling method. Marketing Letters 3(3): 259-272.

HUSSON, F., LÊ, S. and PAGÈS, J. 2011. Exploratory multivariate analysis by example using $R$. Boca Raton, CRC Press.

HUSSON, F., JOSSE, J., LE, S. and MAZET, J. 2016. FactoMineR: Multivariate Exploratory Data Analysis and Data Mining. R package version 1.32.

IUCN, \& WBCSD. 2012. Water for Business: Initiatives Guiding Sustainable Water Management in the Private Sector (3rd edition). Gland and Geneva.

JAUNG, W., PUTZEL, L., BULL, G.Q., KOZAK, R. and ELLIOTT, C. 2016. Forest Stewardship Council certification for forest ecosystem services: An analysis of stakeholder adaptability. Forest Policy and Economics 70: 91-98.

KAISER, H.F. 1960. The application of electronic computers to factor analysis. Educational and psychological measurement.

KANOWSKI, P.J., MCDERMOTT, C.L. and CASHORE, B.W. 2011. Implementing REDD+: lessons from analysis of forest governance. Environmental Science \& Policy 14(2): 111-117.

KEMKES, R.J., FARLEY, J. and KOLIBA, C.J. 2010. Determining when payments are an effective policy approach to ecosystem service provision. Ecological Economics 69(11): 2069-2074.

KERR, J. 2002. Watershed Development, Environmental Services, and Poverty Alleviation in India. World Development 30(8): 1387-1400.

KOZAK, R.A., COHEN, D.H., LERNER, J. and BULL, G.Q. 2004. Western Canadian consumer attitudes towards certified value-added wood products: An exploratory assessment. Forest Products Journal 54(9): 21-24.

LANDELL-MILLS, N. and PORRAS, I.T. 2002. Silver bullet or fools' gold? A global review of markets for forest environmental services and their impact on the poor. London, International Institute for Environment and Development.

LE ROUX, B. and ROUANET, H. 2010. Multiple correspondence analysis, Sage.

LITWIN, M.S., HAYS, R.D., FINK, A., GANZ, P.A., LEAKE, B. and BROOK, R.H. 1998. The UCLA Prostate Cancer Index - Development, reliability, and validity of a health-related quality of life measure. Medical Care 36(7): 1002-1012.
MA (Millennium Ecosystem Assessment). 2005. Ecosystems and Human Well-being: Synthesis. Washington, DC.: Island Press.

MARTÍN-LÓPEZ, B., GARCÍA-LLORENTE, M., PALOMO, I. and MONTES, C. 2011. The conservation against development paradigm in protected areas: Valuation of ecosystem services in the Doñana social-ecological system (southwestern Spain). Ecological Economics 70(8): 1481-1491.

MACCALLUM, R.C., WIDAMAN, K.F., ZHANG, S. and HONG, S. 1999. Sample size in factor analysis. Psychological methods 4(1): 84.

MACDONALD, R. and JOLLIFFE, L. 2003. Cultural rural tourism: Evidence from Canada. Annals of Tourism Research 30(2): 307-322.

MEDJIBE, V.P., PUTZ, F. and ROMERO, C. 2013. Certified and Uncertified Logging Concessions Compared in Gabon: Changes in Stand Structure, Tree Species, and Biomass. Environmental Management 51(3): 524-540.

MEIJAARD, E., SHEIL, D., GUARIGUATA, M.R., NASI, R., SUNDERLAND, T.C.H. and PUTZEL, L. 2011. Ecosystem services certification: Opportunities and constraints. Bogor, Indonesia, Center for International Forestry Research (CIFOR): $57 \mathrm{p}$.

MEIJAARD, E., WUNDER, S., GUARIGUATA, M.R. and SHEIL, D. 2014. What scope for certifying forest ecosystem services? Ecosystem Services 7(0): 160-166.

MERGER, E., DUTSCHKE, M. and VERCHOT, L. 2011. Options for REDD+ Voluntary Certification to Ensure Net GHG Benefits, Poverty Alleviation, Sustainable Management of Forests and Biodiversity Conservation. Forests 2: 550-577.

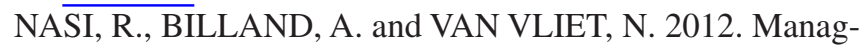
ing for timber and biodiversity in the Congo Basin. Forest Ecology and Management 268(0): 103-111.

NICKERSON, N.P., BLACK, R.J. and MCCOOL, S.F. 2001. Agritourism: Motivations behind Farm/Ranch Business Diversification. Journal of Travel Research 40(1): 19-26.

NUSSBAUM, R. and SIMULA, M. 2013. The Forest Certification Handbook. London and Sterling, Earthscan.

OSBORNE, J.W. and COSTELLO, A.B. 2004. Sample size and subject to item ratio in principal components analysis. Practical Assessment, Research \& Evaluation 9(11): 8.

PAGIOLA, S. 2008. Payments for environmental services in Costa Rica. Ecological Economics 65(4): 712-724.

PETTENELLA, D. and BROTTO, L. 2012. Governance features for successful REDD+ projects organization. Forest Policy and Economics 18: 46-52.

RAMETSTEINER, E. and SIMULA, M. 2003. Forest certification-an instrument to promote sustainable forest management? Journal of Environmental Management 67(1): 87-98.

RAUUDSEPP-HEARNE, C., PETERSON, G.D., BENNETT, E.M. and MOONEY, H.A. 2010. Ecosystem service bundles for analyzing tradeoffs in diverse landscapes. Proceedings of the National Academy of Sciences of the United States of America 107(11): 5242-5247. 
REVELLE, W. 2015. psych: Procedures for Psychological, Psychometric, and Personality Research. Evanston, Illinois, Northwestern University.

ROBERTSON, M., BENDOR, T.K., LAVE, R., RIGGSBEE, A., RUHL, J.B. and DOYLE, M. 2014. Stacking ecosystem services. Frontiers in Ecology and the Environment 12(3): 186-193.

RODRÍGUEZ, J.P., BEARD, T.D., BENNETT, E.M., CUMMING, G.S., CORK, S.J., AGARD, J., DOBSON, A.P. and PETERSON, G.D. 2006. Trade-offs across Space, Time, and Ecosystem Services. Ecology and Society 11(1): 28.

SHANLEY, P., PIERCE, A.R., LAIRD, S.A. and ROBINSON, D. 2008. Beyond timber: certification and management of non-timber forest products. Bogor, Indonesia, Center for International Forestry Research (CIFOR).

SHARPLEY, R. and VASS, A. 2006. Tourism, farming and diversification: An attitudinal study. Tourism Management 27(5): 1040-1052.

STERNER, T. and CORIA, J. 2012. Policy Instruments for Environmental and Natural Resource Management. Washington, DC, RFF Press.

STUPAK, I., LATTIMORE, B., TITUS, B.D. and TATTERSALL SMITH, C. 2011. Criteria and indicators for sustainable forest fuel production and harvesting: A review of current standards for sustainable forest management. Biomass and Bioenergy 35(8): 3287-3308.

TENENHAUS, M. and YOUNG, F. 1985. An analysis and synthesis of multiple correspondence analysis, optimal scaling, dual scaling, homogeneity analysis and other methods for quantifying categorical multivariate data. Psychometrika 50(1): 91-119.
THOMPSON, B. 2004. Exploratory and confirmatory factor analysis: Understanding concepts and applications, Washington, DC, American Psychological Association.

TSANGA, R., LESCUYER, G. and CERUTTI, P.O. 2014. What is the Role for Forest Certification in Improving Relationships between Logging Companies and Communities? Lessons from FSC in Cameroon. International Forestry Review 16(1): 14-22.

TUOMINEN, M., RAJALA, A. and MOLLER, K. 2004. How does adaptability drive firm innovativeness? Journal of Business Research 57(5): 495-506.

VALENTIN, C.D., EMRICH, A., WERTH, D. and LOOS, P. 2012. Conceiving Adaptability for Business Models: A Literature-based Approach. CONF-IRM 2012 Proceedings. Paper 50.

VAN DAM, J., JUNGINGER, M. and FAAIJ, A.P.C. 2010. From the global efforts on certification of bioenergy towards an integrated approach based on sustainable land use planning. Renewable and Sustainable Energy Reviews 14(9): 2445-2472.

VOGT, K.A., LARSON, B.C., GORDON, J.C., VOGT, D.J. and FANZERS, A. 2000. Forest Certification: Roots, Issues, Challenges, and Benefits. New Haven, School of Forestry and Environmental Studies, Yale University.

WENDLAND, K.J., HONZÁK, M., PORTELA, R., VITALE, B., RUBINOFF, S. and RANDRIANARISOA, J. 2010. Targeting and implementing payments for ecosystem services: Opportunities for bundling biodiversity conservation with carbon and water services in Madagascar. Ecological Economics 69(11): 2093-2107.

WOODWARD, R.T. 2011. Double Dipping in Environmental Markets. Journal of Environmental Economics and Management 61: 153-169. 